\title{
Reaction of a sea snake (Hydrophis major) to contact with a sea anemone
}
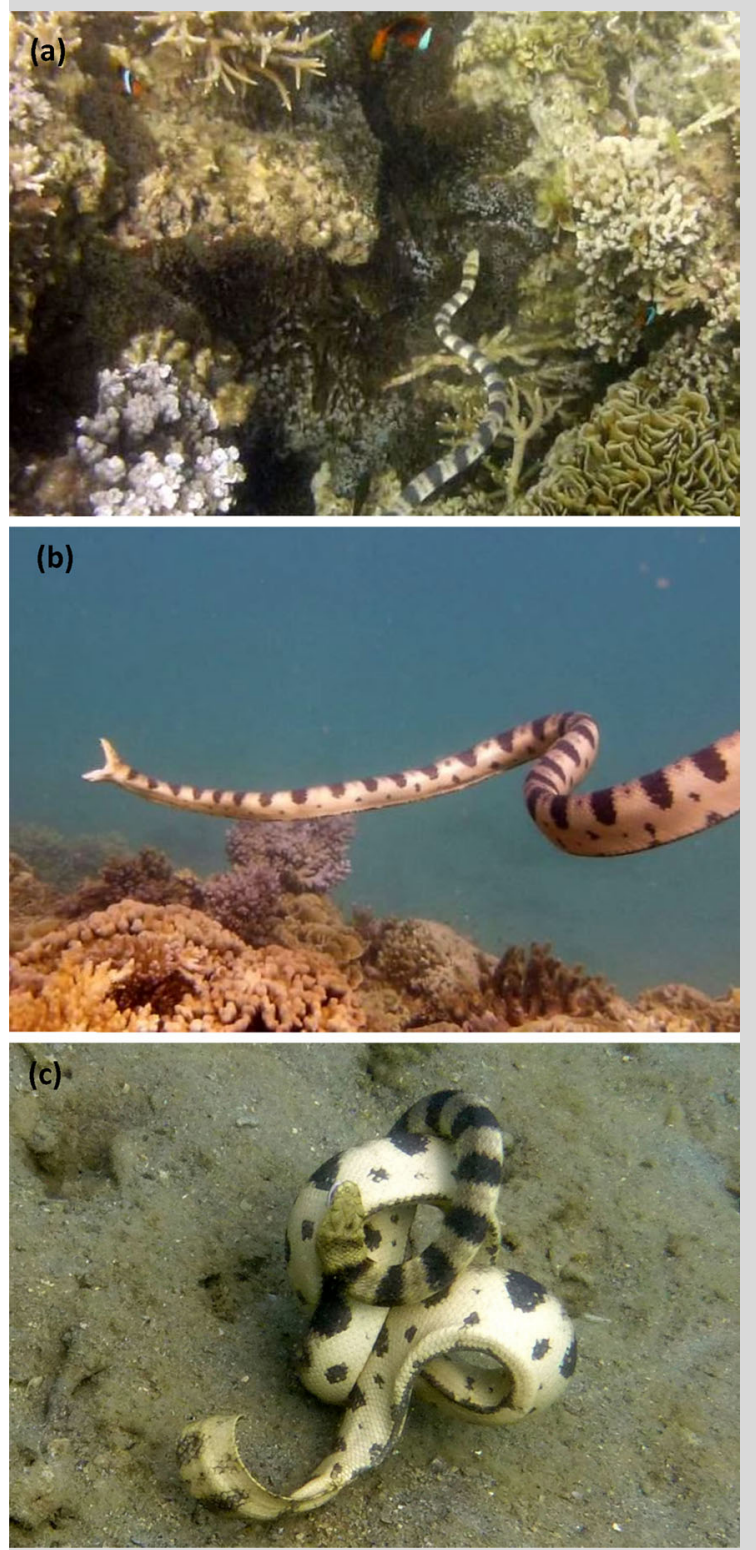

Anemones and anemonefish are common in coral reef ecosystems. Anemonefish retreat to their host at the approach of a predator, presumably exploiting the anemone's cnidoblast laden tentacles as a defense, but evidence for that benefit is scarce. During longterm studies of sea snake behavior, we have not previously seen them contact an anemone. That lack of contact suggests active avoidance by the snakes, supported by a case where a juvenile turtle-headed sea snake Emydocephalus annulatus was apparently captured and killed by an anemone (Ineich and Laboute 2002). However, this small slow-swimming snake species feeds only on fish eggs and thus poses no threat to adult fishes (Goiran et al. 2013). During studies on the Baie des Citrons fringing reef (Noumea, New Caledonia: $22^{\circ} 18^{\prime} 05^{\prime \prime} \mathrm{S}, 166^{\circ} 26^{\prime} 13^{\prime \prime} \mathrm{E}$ ), we saw an adult piscivorous sea snake exhibit extreme distress immediately after touching an anemone.

On February 3, 2014, at 0907 hrs, one of us (CG) videotaped an adult (approx. $1 \mathrm{~m}$ snout-vent length) female greater sea snake, Hydrophis major, as she foraged on a reef flat (see Electronic Supplementary Material). Initially, the snake displayed normal foraging behavior (rapid swimming, tongue flicking, investigating crevices). An anemone, Entacmaea quadricolor, inhabited by the anemonefish Amphiprion melanopus (both identified from Fautin and Allen 1992), was mostly inside a crevice, and the snake probably did not see it before touching it with its head (and probably, extruded tongue; Fig. 1a). Beginning $9 \mathrm{~s}$ later, the snake opened its mouth widely as if trying to dislodge an object that was causing irritation (Fig. 1b) and then writhed about, tying its body in knots (Fig. 1c). At one point, the snake bit its own body. During this uncontrolled writhing, the snake entered deeper water and sank toward the sandy substrate. After about $2 \mathrm{~min}$, the snake resumed foraging.

These observations, although involving only a single potential predator, demonstrate that the toxins of sea anemones can indeed repel piscivorous snakes. The dramatic responses of the greater sea snake suggest that an anemone's tentacles do indeed provide a safe harbor for otherwise vulnerable fishes.

Acknowledgments We thank Luc Faucompré for his help with video.

\section{Electronic supplementary material}

Below is the link to the electronic supplementary material.Supplementary material 1 (MP4 $159094 \mathrm{~kb})$.

References

Fautin DG, Allen GR (1992) Field guide to anemonefishes and their host sea anemones. Western Australian Museum, Perth

Goiran C, Dubey S, Shine R (2013) Effects of season, sex and body size on the feeding ecology of turtle-headed sea snakes (Emydocephalus annulatus) on IndoPacific inshore coral reefs. Coral Reefs 32:527-538

Ineich I, Laboute P (2002) Les serpents marins de Nouvelle-Calédonie. IRD éditions, Paris

Fig. 1 a An adult female greater sea snake encounters and apparently tongue flicks an anemone. b Soon thereafter, she recoils and gapes widely. c She writhes about in an uncoordinated fashion

Electronic supplementary material The online version of this article (doi:10.1007/s00338-014-1161-2) contains supplementary material, which is available to authorized users.

C. Goiran $(\bowtie)$

Labex Corail, Université de la Nouvelle-Calédonie, BP R4, 98851 Nouméa Cedex, New Caledonia

e-mail: claire.goiran@univ-nc.nc

R. Shine

Biological Sciences A08, University of Sydney, Sydney, NSW 2006, Australia

Received: 23 February 2014/Accepted: 15 April 2014/Published online: 3 May 2014

Coral Reefs (2014) 33:793

(C) Springer-Verlag Berlin Heidelberg 2014

DOI $10.1007 / \mathrm{s} 00338-014-1161-2$ 